\title{
CONTRACTILITY OF ACTOMYOSIN BANDS PREPARED FROM NORMAL AND FAILING HUMAN HEARTS ${ }^{1}$
}

\author{
By K. KAKO and R. J. BING
}

(From the Department of Medicine, Washington University School of Medicine, and the Washington University Medical Service, Veterans Administration Hospital, St. Louis, Mo.)

(Submitted for publication July 25, 1957 ; accepted November 14, 1957)

Previous work from this laboratory has indicated that actomyosin bands prepared from heart muscle of dogs preserve undiminished contractility for one hour after the death of the animal (1). This suggested the possibility of investigating the contractile properties of actomyosin bands from human hearts obtained at autopsy. Such a study would make possible a comparison of actomyosin prepared from normal human heart muscle with that obtained from heart muscle of patients who had died of congestive heart failure. The method could also be used to obtain information on the effect of cardiac glycosides and other drugs on the contractile elements of normal and failing human heart muscle. To the present, only actomyosin preparations from hearts with artificially produced failure have been studied $(2,3)$. In these "models" obtained from dogs' hearts, the mechanism and nature of failure may vary from that encountered in man.

The present report deals with a comparison of the contractile properties of actomyosin prepared from normal and failing human hearts and with the effect of calcium chloride and digoxin and the action of nicotine on these preparations.

\section{MATERIAL AND METHODS}

Actomyosin solution was prepared in the cold $\left(4^{\circ}\right.$ C. $)$ as follows: The heart was minced with scissors and $10 \mathrm{Gm}$. of the muscle was homogenized in a Waring blendor for three minutes with a fourteenfold volume of WeberEdsall solution. The muscle was then extracted for 24 hours at $6^{\circ} \mathrm{C}$. after addition of $20 \mathrm{mg}$. of the disodium salt of adenosine triphosphate (ATP). After extraction, the homogenate was mixed gently and $150 \mathrm{ml}$. of WeberEdsall solution was added. The mixture was then centrifuged in the cold at $4,000 \mathrm{rpm}$ for 15 minutes. The

1 Work supported by United States Public Health Service Grant No. H-2678, The Life Insurance Medical Research Fund; The American Heart Association; Burroughs Wellcome and Co., Inc.; and The Tobacco Industry Research Fund. supernatant fluid was again centrifuged at 4,000 rpm for 10 minutes. Following this, the supernatant fluid was diluted with a fivefold volume of triple glass distilled water; the $\mathrm{pH}$ was adjusted to 7.0 by careful addition of $1 / 10 \mathrm{~N}$ acetic acid. Usually, $17 \mathrm{ml}$. of the acid was sufficient. The solution was then centrifuged at 1,500 rpm for 30 minutes. The supernatant was discarded and the precipitate was suspended in about $20 \mathrm{ml}$. of triple glass distilled water and centrifuged again for $15 \mathrm{~min}$ utes. The precipitate was dissolved in $2 \mathrm{M} \mathrm{KCl}$ to a final concentration of $0.5 \mathrm{M} \mathrm{KCl}$. One $\mathrm{ml}$. of this solution was used for the formation of actomyosin bands. The solution was pipetted on the surface of a glass slide, from which it was transferred into a solution contained in a Langmuir trough. This trough solution contained $0.05 \mathrm{M} \mathrm{KCl}$ and $0.001 \mathrm{M}$ magnesium chloride, and was buffered to a $\mathrm{pH}$ of 7.5 with $1 / 100 \mathrm{M}$ barbital buffer. The temperature in the trough was kept at $24^{\circ} \mathrm{C}$.

The technique for the formation of bands has been previously described (4). However, since certain modifications were used, the method is briefly summarized at this point. The protein solution spread on the surface of the trough was compressed between two wooden sticks into bands, and then pushed gently into the contraction chamber containing $40 \mathrm{ml}$. of the trough solution (Figure 1). One end of the band was firmly fixed in position by a rigid connection with the bottom of the trough (Figure 1). The other end of the band was attached to the elongated arm of a Roller Smith torsion balance. The length of the band was approximately $2 \mathrm{~cm}$., the width about $5 \mathrm{~mm}$. Only afterloaded contractions were studied. The band was loaded by moving the weighing spring of the torsion balance by the desired number of $\mathrm{mg}$. (between 5 to $25 \mathrm{mg}$.). ATP was now added to the contraction chamber to make a final concentration of $0.005 \mathrm{M}$. As the protein band contracted upon the addition of ATP, the arm of the torsion balance followed the contraction. This initiated an electronic Servo feedback mechanism which moved the trough in a direction opposite to that of the contraction. Thus, the arm of the torsion balance was always kept in equilibrium position and a counter force was produced which equalized in every instance the tension of the thread. The movements of the trough were recorded on paper with an inkwriter. With this method, one can record without appreciable friction, shortening of the band at a magnification of 23 diameters. Percentage of shortening of the bands was calculated by dividing the amount of contrac- 


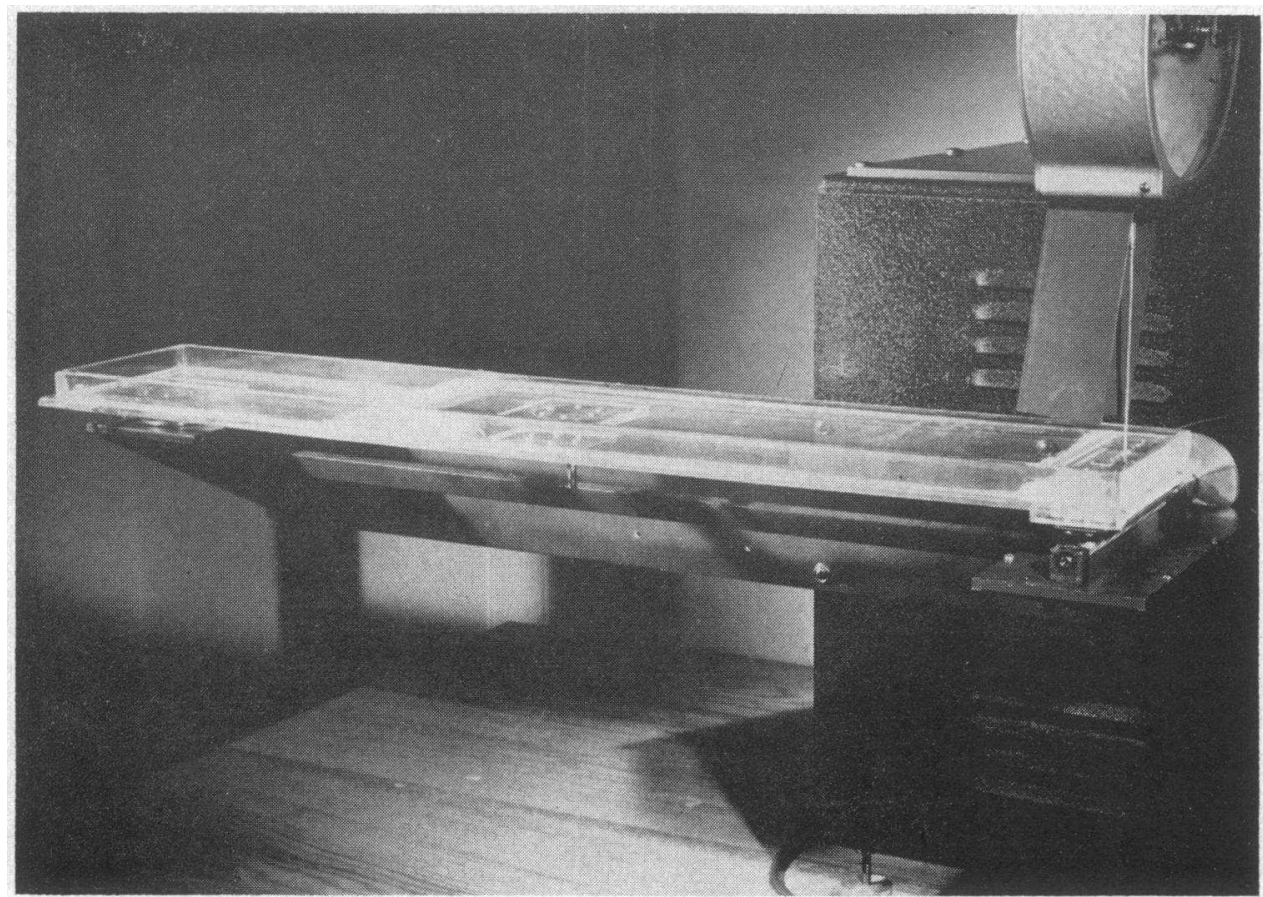

Fig. 1. The Langmuir Trough in Which the Actomyosin Solution Is Compressed INTO BANDS

The contraction chamber is at the right. The torsion balance and its elongated arm are also shown. As the protein band contracts, the elongated arm of the torsion balance moves with the contraction; the trough moves in an opposite direction. Thus, the counter force produced equalizes the tension on the bands.

tion ( $\mathrm{mm}$.) by the initial length of the band 30 minutes after addition of ATP. All contractions were expressed per mg. of load. Results were subjected to statistical analysis. Regression lines were calculated for each series of experimental conditions and the significance of the regression coefficient was obtained with standard procedures (5). The group means and regression coefficients thus obtained were tested for significant differences from the control group (hearts obtained from patients without heart failure, without addition of digitalis, calcium chloride, or nicotine). To determine whether the interval between death of the patient and time of extraction of actomyosin alters the contraction of the bands, individual regression lines were obtained for each of these time intervals, and the regression lines were tested for significant differences between both the group means and the regression coefficient (5).

Material was obtained at autopsy from human heart muscle. Ten to twenty $\mathrm{Gm}$. of muscle were excised, the pericardium was discarded, and the muscle was chopped into small pieces and placed in crushed ice. Homogenates were then made and preparation of actomyosin was carried out in the manner described above. The material was collected from 41 hearts at periods ranging from one to six hours after death of the patient. Twelve of the patients had died from congestive heart failure due to arteriosclerotic or hypertensive heart disease. The remainder died from malignancy, cirrhosis of the liver, leukemia, peptic ulcer, or cerebral vascular accident.

\section{RESULTS}

Before comparative studies on contraction of actomyosin bands from human hearts could be carried out, it had to be ascertained that prolonged intervals between death of the patient and preparation of actomyosin did not affect the contractility of the protein. The experiments revealed no significant differences between the fresh preparation and that obtained from one to six hours after death. (Differences among the group mean $\mathrm{p}>$ 0.05.) This applies to actomyosin prepared from both normal and failing human hearts.

Figure 2 illustrates the findings obtained on actomyosin prepared from heart muscle of patients who had died without clinical evidence of heart failure. As the load on the protein band increased, the percentage shortening diminished. The relationship between load and percentage shortening was maintained after nicotine had been added to the contraction chamber (Figure 3 ). 
However, the degree of shortening of the bands was less per mg. load than in the control series (Figure 3). The effect of digoxin with and without the addition of calcium chloride as well as of calcium chloride alone is illustrated in Figure 4. Neither calcium chloride nor digoxin appeared to influence the contractility of the protein band. However, calcium chloride in combination with digoxin increased the contractility of actomyosin prepared from normal human hearts. Most of the values lie on the positive side of the regression line and several are above the standard deviation of the normal. The slope of the regression line is

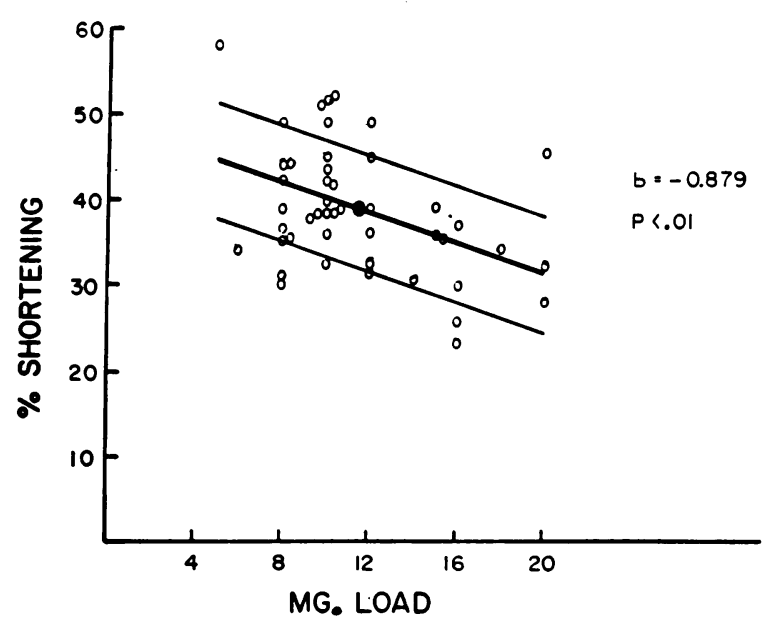

Fig. 2. The Relationship Between Load and Percentage Shortening of Nonfailing Human Hearts

It may be seen that the scatter of data is moderate and that there is a significant relationship between load and percentage shortening. The large black symbol represents the group mean, the heavy center line is the regression line, the two lines parallel to it are the standard deviations.

slightly less than that of the control values; the group mean, on the other hand, is higher than that of the control. This difference is statistically significant $(<0.05)$. Similar results were obtained by Korey and Edman, who demonstrated that the simultaneous addition of calcium chloride and ouabain increased the contractility of glycerinated skeletal muscle strips by 33 per cent $(6,7)$.

The results on 45 actomyosin bands prepared from hearts of patients who died in congestive heart failure are illustrated in Figure 5. Protein bands prepared from these hearts showed a significant reduction in percentage shortening.

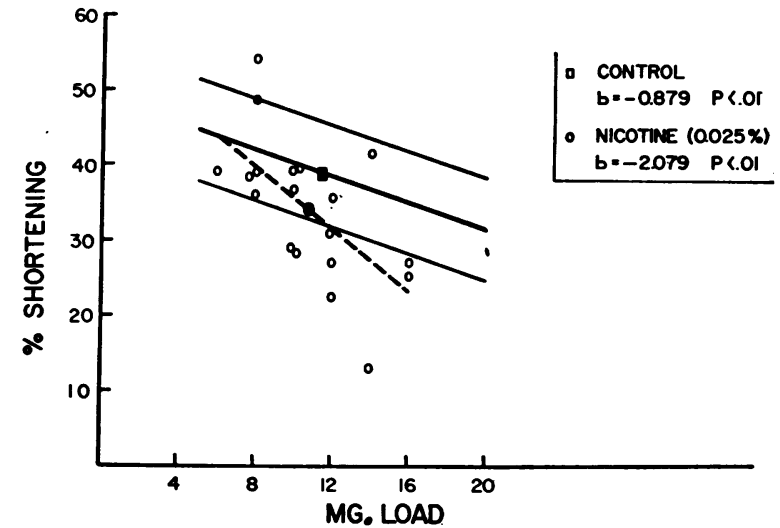

Fig. 3. The Effect of Nicotine on the Reiationship Between Load and Percentage Shortening

The broken line represents the regression line obtained from the data obtained with nicotine. The slope of this line is steeper than that of control and the group mean is lower. The regression line and standard deviations obtained from normal data are again represented.

Many of the data lie below the standard deviation of the normal controls. As in normal hearts, digoxin failed to increase the contractility of actomyosin prepared from failing human hearts (Figure 5). In contrast, the combined addition of digoxin plus calcium chloride resulted again in a significant improvement in contraction of the actomyosin bands (Figure 5). This is illustrated

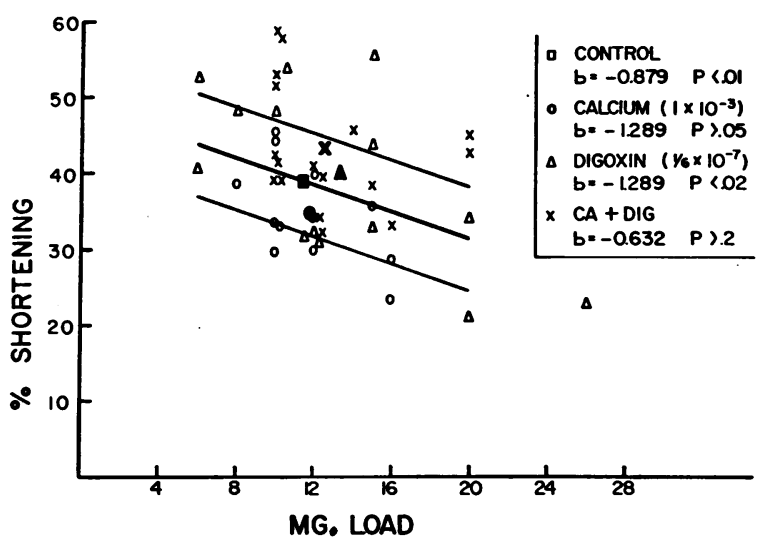

Fig. 4. The Effect of Calcium, Digoxin, and Calcium and Digoxin Combined on Actomyosin Bands FROM NORMal Hearts

The normal regression line and standard deviations are again represented. The group means of calcium and digoxin added separately (indicated by the heavy mark) are close to the group means of the normal. The group mean for calcium and digoxin combined is significantly higher than the normal group mean. 


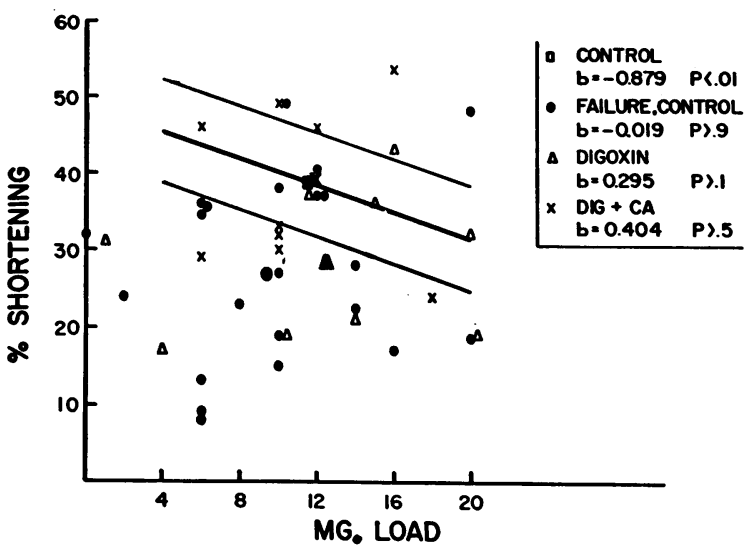

Fig. 5. The Contractility of Actomyosin Bands Prepared from failing Human Hearts and the EfFeCt of Digoxin, and of Calcium and Digoxin ComBINED

The regression line and standard deviations obtained from normal data are again represented. Many of the points obtained from failing hearts are below the standard deviation of the normal. Digoxin does not influence the percentage shortening (the group mean is still below the deviation of normal data). The combination of digoxin and calcium results in marked improvement of contractility as indicated by the fact that the group mean is now on the normal regression line.

by the fact that the group mean of this experimental series is 39 per cent for a load of $11.8 \mathrm{mg}$. This is identical with the group mean of the values obtained from normal hearts (Figure 1). Apparently, the glycoside combined with calcium chloride restores the contractility of actomyosin bands of failing human hearts to normal.

\section{DISCUSSION}

The data reveal that the contractility of actomyosin bands prepared from human hearts remains undiminished for at least six hours after death of the patient. Apparently, the contractile proteins of the human heart are even more resistant to autolysis than are ATP or the respiratory enzymes of heart muscle which are inactive three hours after death $(8,9)$.

A reverse relationship exists between load and percentage shortening of actomyosin bands prepared from human heart muscle (Figure 2). This relationship is maintained after the addition of nicotine, although shortening of the bands is less than in the control series (Figure 3 ). The effect of nicotine is so slight that a direct effect of this drug on the contractile proteins of the heart cannot be postulated. This observation is in line with previously published data on the effect of nicotine on the isolated heart $(10,11)$.

Digoxin and calcium chloride, when added separately to the actomyosin solution or the contraction chamber, fail to influence the contractility of actomyosin bands prepared from either normal or failing human hearts. These observations are in agreement with those obtained by several authors. Korey, for example, demonstrated that digoxin does not change shortening of glycerinated skeletal muscle strips and Stutz, Feigelson, Emerson, and Bing have shown that lanatoside-C influences neither the force nor the speed of contracting glycerinated heart muscle $(6,12)$. No effect of digoxin on the length-resting tension relationship of glycerinated heart muscle could be demonstrated (12). Similar results were obtained by Edman (7); Benson found that digitalis does not reverse the changes in cardiac actomyosin observed in artificially produced congestive failure (3). Other workers, however, noticed that cardiac glycosides influence the speed and force of actomyosin threads $(13,14)$. It is likely that these discrepancies are the result of differences in technique and in the preparation of actomyosin

The results reported in this paper illustrate that the combination of calcium and glycoside leads to an increase in contractility of actomyosin bands prepared from both failing and nonfailing human heart muscle. It has long been known that in the frog heart $\mathrm{CaCl}_{2}$ is essential for the activity of cardiac glycosides. Loewi was of the opinion that the glycosides sensitize the myocardium to the action of calcium chloride (15). Potentiation of the effect of digitalis by calcium ion has been demonstrated in the frog heart, the Langendorff, and the heart-lung preparations (16-19). The mechanism of the synergistic action between $\mathrm{CaCl}_{2}$ and the glycosides is not known. Wilbrandt is of the opinion that changes in extracellular $\mathrm{CaCl}_{2}$ produce an alteration in the intracellular concentrations of the ion (20); the contractility of actomyosin would thus be increased by influencing the ATP-ase activity of this protein. Bozler has demonstrated that the glycerol extracted muscle 
fiber takes up $\mathrm{CaCl}_{2}$ from a dilute solution of this salt, but where and how $\mathrm{CaCl}_{2}$ is bound to the muscle protein has not been ascertained (21). Ellis has shown, however, that the positive inotropic effect of $\mathrm{CaCl}_{2}$ and digitalis is not dependent upon the functional integrity of oxidative metabolism of the cell (22).

Actomyosin bands prepared from failing human hearts demonstrate a marked diminution in contractility. It is not possible to state at this point whether this is the result of changes in contractile proteins of the failing heart. However, Benson had previously noted that in dogs with experimental heart failure there occurred a decrease in concentration of actomyosin, diminished viscosity per unit of actomyosin, and decreased viscosity response to the addition of ATP (3). He ascribed these changes to alterations in the organization of actomyosin, more specifically to the presence of myosin uncombined with actin. The dissociated state of actomyosin may be due to physical changes in heart muscle. Olson concluded that heart failure in dogs leads to marked changes in the physical-chemical properties of myosin consistent with a sizable increase in molecular weight (2). The results reported in this paper, although confirming the existence of changes in actomyosin of failing hearts, permit no conclusions on the nature of these alterations. It is likely, however, that the observed differences between the contractility of actomyosin prepared from normal and failing hearts are due to changes in the heart muscle prior to extraction. It is difficult to visualize, for example, how the failing heart muscle could be more susceptible to autolysis than muscle prepared from nonfailing hearts.

\section{SUM MARY}

Actomyosin bands were prepared from normal and failing human hearts obtained at necropsy. ATP-induced afterloaded contractions were recorded without friction by means of a new null seeking device.

The time interval (two to six hours) between death of the patient and the preparation of actomyosin did not affect the shortening of the actomyosin bands.

Actomyosin bands prepared from normal hearts demonstrated a reverse relationship between load and percentage shortening. Nicotine caused a slight diminution in the contractility of the bands, while $\mathrm{CaCl}_{2}$ and digoxin, when added separately, had no effect. When combined, $\mathrm{CaCl}_{2}$ and digoxin increased the shortening of the bands.

The contractility of actomyosin bands prepared from failing human hearts was significantly diminished. Digoxin failed to correct this defect, but the combination of digoxin and $\mathrm{CaCl}_{2}$ restored shortening of the bands to normal.

\section{REFERENCES}

1. Dettli, L., and Bing, R. J. Contractility and extractability of heart actomyosin after death. Circulat. Res. 1956, 4, 519.

2. Olson, R. E. Editorial: Molecular events in cardiac failure. Amer. J. Med. 1956, 20, 159.

3. Benson, E. S. Composition and state of protein in heart muscle of normal dogs and dogs with experimental myocardial failure. Circulat. Res. 1955, 3, 221.

4. Dettli, L., and Bing, R. J. Contractile properties of actomyosin threads and bands prepared from dogs' hearts. Amer. J. Physiol. 1956, 187, 145.

5. Snedecor, G. W. Statistical Methods. Ames, The Collegiate Press, Inc., 1946.

6. Korey, S. Some factors influencing the contractility of a nonconducting fiber preparation. Biochim. biophys. Acta 1950, 4, 58.

7. Edman, K. A. P. The action of cardiac glycosides on the ATP-induced contraction of glycerinated muscle fibers. Acta physiol. scand. 1953-54, 30, 69.

8. Bate-Smith, E. C., and Bendall, J. R. Changes in muscle after death. Brit. med. Bull. 1956, 12, 230.

9. Beuren, A., Choudhury, J. D., and Bing, R. J. Studies on the persistence of metabolic functions on the heart after death. In preparation.

10. Mansfeld, G., and Hecht, K. Untersuchungen ueber die Wirkung des Tabakrauchens auf das HerzLungenpraeparat von Hunden. Naunyn-Schmiedeberg's Arch. exp. Path. Pharmak. 1933, 172, 362.

11. Strauss, L. H. Nicotinwirkungen und- schaedigungen. Ergebn. inn. Med. Kinderheilk. 1937, 52, 375.

12. Stutz, H., Feigelson, E., Emerson, J., and Bing, R. J. The effect of digitalis (Cedilanid) on the mechanical and electrical activity of extracted and nonextracted heart muscle preparations. Circulat. Res. 1954, 2, 555.

13. Robb, J. S., and Malloy, S. Effect of ouabain on the actomyosin threads. J. Pharmacol. exp. Ther. 1953, 108, 251.

14. Bowen, W. J. Effect of digoxin upon rate of shortening of myosin B threads. Fed. Proc. 1952, 11, 16. 
15. Loewi, O. Ueber den Zusammenhang zwischen Digitalis- und Kalziumwirkung. Naunyn-Schmiedeberg's Arch. exp. Path. Pharmak. 1918, 82, 131.

16. Nyiri, W., and du Bois, L. Experimental studies on heart tonics. III. The relationships of calcium ions, hydrogen ions and digitalis. J. Pharmacol. exp. Ther. 1930, 39, 111.

17. Wiechmann, E. Ueber die Beseitigung von Giftwirkungen am Herzen durch Calcium und andere zweiwertige Kationen. Pflüg. Arch. ges. Physiol. 1922, 195, 588.

18. Baker, W. W., and Baker, J. M. Effects of epinephrine and calcium on the electrogram of the ouabainized frog heart. Circulat. Res. 1955, 3, 274.
19. Baker, J. B. E. The influence of calcium and potassium ions on the toxicity of ouabain. Brit. J. Pharmacol. 1947, 2, 259.

20. Wilbrandt, W. Zum Wirkungsmechanismus der Herzglykoside. Schweiz. med. Wschr. 1955, 85, 315.

21. Bozler, E. Binding of calcium and magnesium by the contractile elements. J. gen. Physiol. 1954-55, 38, 735.

22. Ellis, S. The importance of metabolic pathways for the positive inotropic actions of cardiac glycosides and calcium ions. J. Pharmacol. exp. Ther. 1953, 109, 233. 